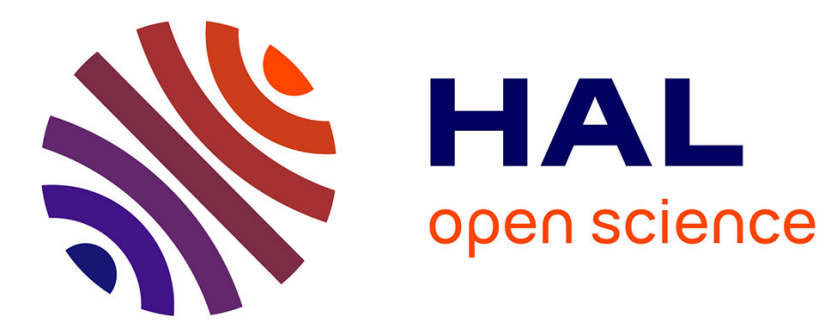

\title{
Synchronization of nanowire self-oscillators
}

Anthony Ayari, Thomas Barois, Sorin Perisanu, Pascal Vincent, Stephen

\author{
Purcell
}

\section{To cite this version:}

Anthony Ayari, Thomas Barois, Sorin Perisanu, Pascal Vincent, Stephen Purcell. Synchronization of nanowire self-oscillators. General Assembly and Scientific Symposium (URSI GASS), 2014 XXXIth URSI, Aug 2014, Beijing, China. 10.1109/URSIGASS.2014.6929481 hal-01565126

\section{HAL Id: hal-01565126 \\ https://hal.science/hal-01565126}

Submitted on 17 Dec 2018

HAL is a multi-disciplinary open access archive for the deposit and dissemination of scientific research documents, whether they are published or not. The documents may come from teaching and research institutions in France or abroad, or from public or private research centers.
L'archive ouverte pluridisciplinaire HAL, est destinée au dépôt et à la diffusion de documents scientifiques de niveau recherche, publiés ou non, émanant des établissements d'enseignement et de recherche français ou étrangers, des laboratoires publics ou privés. 


\title{
Synchronization of nanowire self-oscillators
}

\author{
Anthony Ayari*1, Thomas Barois ${ }^{1}$, Sorin Perisanu ${ }^{1}$, Pascal Vincent ${ }^{1}$ and Stephen Purcell ${ }^{1}$ \\ ${ }^{1}$ Institut Lumière Matière, UMR5306 Université Lyon 1-CNRS, Université de Lyon 69622 \\ Villeurbanne cedex, France, anthony.ayari@univ-lyon1.fr
}

Abstract

We performed field emission measurements with $\mathrm{SiC}$ nanowires self-oscillators. Applying an additional AC excitation locks the self-oscillation natural frequency of the nanowire to the external frequency as long as both frequencies do not deviate from each other by more than $10 \%$. An unusual behavior of the phase of the locked self-oscillator is observed showing for instance spontaneous phase modulated signal generation at the nanoscale.

\section{Introduction}

A Nanoelectromechanical system (NEMS) is an electrical device capable of spatial motion at the nanoscale. This type of device is promising for ultrasensitive force and mass detection, in biological applications, and it has potential for miniaturized, very low-power consumption RF switches and time bases, for wireless applications. Several categories of NEMS can self-oscillate either by extrinsic feedback in a phase locked loop type configuration or with an intrinsic nanoscale active mechanism [1-4]. However, after a decade of development, the frequency stability is still the main obstacle for applications that aim to replace the quartz technology. Recently, the NEMS community started to explore the ubiquitous cooperative phenomenon of self-oscillators: synchronization as observed in neurons, heart/breathing systems, population of flashing fireflies, lasers, charge density waves or Josephson junctions. Synchronization can be used for example for signal processing, filters, amplifiers, more sensitive sensors or clinical treatment of Parkinson disease. A major interest of synchronization for RF-NEMS applications is the possibility to stabilize their resonant frequency.

\section{Experimental system}

We studied $\mathrm{SiC}$ semiconductor nanowires with lengths of several tenths of microns and diameters around 100 $\mathrm{nm}$ attached to tungsten tips. The experimental set up consists of a UHV chamber with a scanning electron microscope column. The sample is placed on a XYZ piezoelectric nanomanipulator in front of a counter electrode. A negative DC voltage of about $100 \mathrm{~V}$ is necessary to be in the field emission regime, where electrons tunnel out of the nanowire toward the counter electrode. Above a field emission current of several hundreds of pA the nanowire apex and the field emission current start to self-oscillate. The frequency of oscillation corresponds to the mechanical resonant frequency of the nanowire. This self-oscillation is due to an electromechanical instability of the system as described in details in [2-3]. It can be seen as a positive feedback loop between the position of the wire apex and its voltage and is similar to a vacuum tube oscillator where the role of the grid is played by the position.

\section{Results}

We have applied an additional electrostatic AC force with a counter electrode placed at a few microns of the sample. This force locked the self-oscillation natural frequency of the nanowire to the external frequency as long as both frequencies do not deviate from each other by more than $10 \%$. The difference between both frequencies is called the detuning frequency

\subsection{Arnold tongue}

Synchronization depends on the detuning frequency and on the amplitude of the external force. If the detuning is too important the self-oscillator unlocks or desynchronizes. Generally, increasing the amplitude increases as well the detuning value for unlocking. The region where a self-oscillator can synchronized is called an Arnold tongue and is shown in figure 1 . 


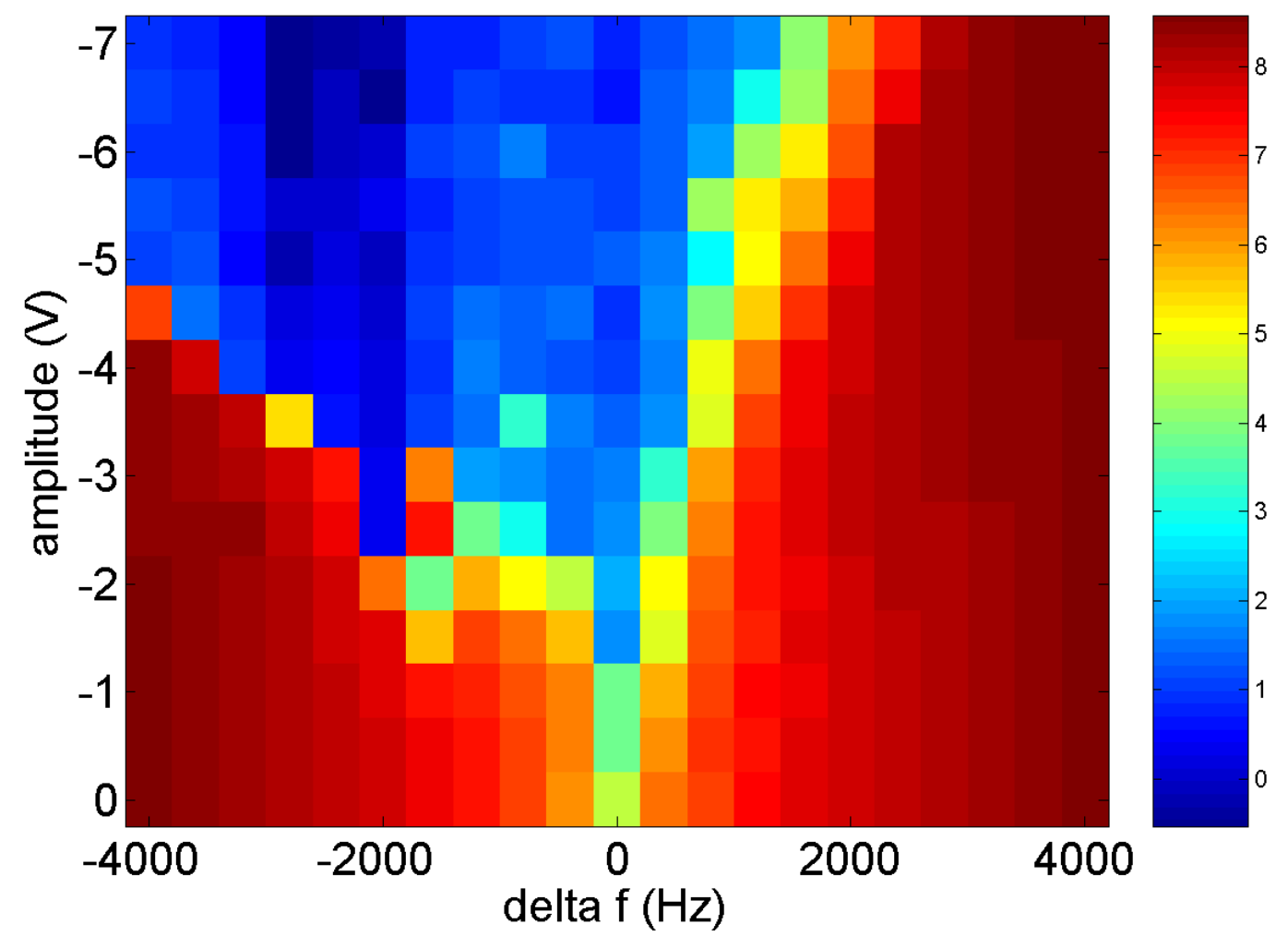

Figure 1: Dephasing diagram for various frequency mismatches (delta f) between selfoscillator frequency and external excitation and various excitation amplitudes in volt. The blue region is the Arnold tongue and corresponds to the locked or synchronized state and the red region to the unlocked state.

\subsection{Phase dynamics}

For strong forcing the self-oscillator can not be described by a single overdamped degree of freedom like the phase. Amplitude of oscillations and phase are coupled which leads to a transition from overdamped to damped and then to phase and amplitude self-oscillations in the rotating frame. The phase dynamics was obtained by Hilbert transform of the field emission current and substration of phase drift due to the external drive in order to be in the rotating frame.

\section{Conclusion}

This paper presented the electromechanical behavior of $\mathrm{SiC}$ nanowires in a field emission configuration. We showed that in the self-oscillation regime, these devices can be synchronized to an external AC signal in a wider range than a simple resonant circuit. This non-linear regime can be used for the generation of frequency modulated signals at the nanoscale.

\section{Acknowledgments}

This work was supported by French National Agency (ANR) through Nanoscience and Nanotechnology Program (Projects NEXTNEMS nºNR-07-NANO-008-01), through "Jeunes Chercheuses et Jeunes Chercheurs" Program (Project AUTONOME n ANR-07-JCJC-0145-01) and CIBLE program of the région Rhône Alpes. The authors acknowledge the support of the "plateforme nanofils et nanotubes lyonnaise de l'Université Lyon 1". We thank the OMNT experts for fruitful discussions.

\section{References}

1. A. Ayari, P. Vincent, S. Perisanu, et al., "Self-Oscillations in Field Emission Nanowire Mechanical Resonators: A Nanometric dc-ac Conversion," Nano Letters, 7, July 2007, pp. 2252-2257.

2. A. Lazarus, T. Barois, S. Perisanu, et al., "Simple modeling of self-oscillations in nanoelectromechanical systems," Applied physics Letters, 96, May 2010, pp. 193114-193116.

3. A. Lazarus, E. de Langre, P. Manneville, et al., "Statics and dynamics of a nanowire in field emission," International Journal of Mechanical Sciences, 52, Nov 2010, pp. 1396-1406.

4. P. G. Steeneken, K. Le Phan, M. J. Goossens, et al., "Piezoresistive heat engine and refrigerator," Nature Physics, 7, Apr 2011, pp. 354-359. 
5. T. Barois, et al., "Role of fluctuations and nonlinearities on field emission nanomechanical self-oscillators," Physical Review B, 88, Nov 2013, pp. 195428.

6. A. Smith and C. Jones, "A Compact, Broadband Antenna," International Symposium on Antennas and Propagation Digest, Atlanta, GA, 2004, pp. 1036-1039.

7. A. Smith and C. Jones, “An Improved Compact, Broadband Antenna," International Symposium on Antennas and Propagation, London, UK, 2005. 